\title{
OPTIMIZATION OF ROSMARINIC ACID EXTRACTION FROM LEMON BALM (Melissa officinalis)
}

\author{
MIROSLAV ONDREJOVIČ ${ }^{1,2}$, HANA BENKOVIČOVÁ ${ }^{1}$, \\ STANISLAV ŠILHÁR ${ }^{2}$ \\ ${ }^{1}$ Department of Biotechnology, University of SS. Cyril and Methodius, J. Herdu 2, \\ Trnava, SK-917 01, Slovak Republic (miroslavondrejovic@gmail.com) \\ ${ }^{2}$ Food Research Institute, dept. Biocentre, Kostolna 7, SK-900 01, Modra, \\ Slovak Republic
}

\begin{abstract}
The aim of this study was optimization of rosmarinic acid extraction from lemon balm (Melissa officinalis). The optimal conditions for the extraction of rosmarinic acid from lemon balm were determined using response surface methodology (RSM). A center composide design (CCD) was used to investigate the effects of three independent variables, namely solid-liquid radio, solvent composition (\%) and extraction temperature $\left({ }^{\circ} \mathrm{C}\right)$. Dependent variable was yield of rosmarinic acid. A second-order polynomial model was used for predicting the response. Optimized conditions for rosmarinic acid were: PEME 1:29 (w/v), temperature $66{ }^{\circ} \mathrm{C}$ a \% propan-2-ol $34 \%$. The experimental values agreed with predicted within a $95 \%$ confidence interval. Yield of rosmarinic acid extraction by these optimized conditions was achieved $72.6 \mathrm{mg}$ of rosmarinic acid / $\mathrm{g}$ of dry extraction matter.
\end{abstract}

Keywords: rosmarinic acid, optimization, Melissa officinalis, extraction

\section{Introduction}

Rosmarinic acid is an ester of caffeic acid and 3,4-dihydroxyphenyllactic acid (PEREIRA et al., 2005; PETERSEN, 1996). It has a number of interesting biological activities, e. g. antimicrobial (PAL BAIS et al., 2002), antiallergic (ITO et al., 1998; MATSUNO et al., 2002), antiviral and anti-inflammatory (GEORGIEV et al., 2006; HUANG et al., 2006; KAMATOU et al., 2005). Rosmarinic acid is commonly found in species of the Boraginaceae and Lamiaceae. The plants with rosmarinic acid content were used in traditional medicine. Today, plant extracts found some application in food and cosmetic industry.

The aim of the present study was to evaluate the effect of changing solvent polarity characterisation using dielectric constant, liquid to solid ratio, temperature and time of extraction on the rosmarinic acid yield in extracts.

\section{Material and methods}

\subsection{Plant material}

Adult leaves of Melissa officinalis were harvested with the twigs and dried at $40^{\circ} \mathrm{C}$. Thereafter, the leaves were separated from the twigs and cut in small squares of $1-1.5 \mathrm{~cm}^{2}$. This extraction material was stored in powder flask at laboratory temperature. 


\subsection{Extraction procedures}

In all experiments, the extractions were done in experimental microtubes and stopped by a rapid decantation of extracts. The impact of solvent composition on the rosmarinic acid content from propanol, ethanol, methanol and their water solution (33 and $66 \% ; \mathrm{v} / \mathrm{v}$ ) to water were explored using extraction by solid-liquid ratio 1:30 $(\mathrm{w} / \mathrm{v})$, at $40{ }^{\circ} \mathrm{C}$ during 1 hour. The influence of the solid-liquid ratios on the extraction was investigated, by considering four ratios $(1: 10,1: 20,1: 30,1: 40 ; \mathrm{w} / \mathrm{v})$ with $33 \%$ $(\mathrm{v} / \mathrm{v})$ water solution of propan-2-ol as extraction solvent. A kinetic study was performed to select reach an asymptotic region in the extraction. The axial (40 and 80 $\left.{ }^{\circ} \mathrm{C}\right)$ and central $\left(60{ }^{\circ} \mathrm{C}\right)$ temperatures were used in this kinetic study. The solid-liquid ratio was 1:100 and extraction solvent was again $33 \%(\mathrm{v} / \mathrm{v})$ water solution of propan2-ol.

\subsection{Experimental design for the response surface methodology (RSM)}

The RSM used a three-factor and central composite design in three blocks consisting of 17 experimental runs with three replicated at the centre point. The design variables were the solid-liquid ratio $\left(0.019-0.099 \mathrm{~g} / \mathrm{ml} ; \mathrm{X}_{1}\right)$, the propan-2-ol proportion (propan-2-ol: water, $\left.1-95 \%, \mathrm{v} / \mathrm{v} ; \mathrm{X}_{2}\right)$ and the temperature $\left(20-80{ }^{\circ} \mathrm{C}\right.$; $\left.\mathrm{X}_{3}\right)$. The variables particle size $(<0.5 \mathrm{~mm})$ and extraction time (1 hour) were kept at constant values.

Experimental data were fitted to the following second-order polynomial model (Eq. 1) and regression coefficients were obtained.

$$
Y=b_{0}+\sum_{i=1}^{k} b_{i} X_{i}+\sum_{i=1}^{k} b_{i i} X_{i}^{2}+\sum_{\substack{i=1 \\ i<j}}^{k-1} \sum_{j=2} b_{i j} X_{i} X_{j}
$$

where $X_{1}, X_{2}, \ldots, X_{k}$ are the independent variables affecting the response $Y ; b_{0}, b_{i}(i=$ $1,2, . ., k), b_{i i}(i=1,2, \ldots, k)$ and $b_{i j}(i=1,2, \ldots k-1 ; j=2,3, \ldots, k)$ are regression coefficients for intercept, linear, quadratic, and interaction terms, respectively; $\mathrm{k}$ is the number of variables (SILVA et al., 2007).

The optimum conditions of rosmarinic acid extraction were looked by using Statgraphic, 5.1. The verification of the validity and adequacy of the predictive extraction model was carried out in these optimum conditions of solid-liquid ratio, solvent composition and extraction temperature. Three experimental replicates were performed at the optimized conditions and the experimental and predicted values were compared.

\subsection{Determination of rosmarinic acid content}

The rosmarinic acid content in prepared extracts was determined by HPLC analysis using Purospher Star RP18e, $250 \times 4 \mathrm{~mm}, 5 \mu \mathrm{m}$, gradient elution of $0.1 \%$ trifluoracetic acid in water (A) and acetonitrile (B), at flow rate $1 \mathrm{ml} / \mathrm{min}$ : $0 \mathrm{~min} 15 \%$ B, $18 \min 30 \%$ B, $25 \min 80 \%$ B, $27 \min 80 \%$, with detection at $325 \mathrm{~nm}$. Final 
rosmarinic acid content was expressed as mg of rosmarinic acid per g of dry material (DM).

\section{Results and discussion}

\subsection{Selection of optimized extraction parameters}

Extraction efficiency of natural compounds is impacted by multiple parameters such as temperature, time and solvent polarity, among others, and their effects may be either independent or interactive. At the beginning of this study, the factors extraction solvent, solid-liquid ratio, temperature and time of extraction were investigated to determination the appropriate experimental ranges to be considered during the optimization process.

As stated in the literature, for preparation of crude extracts with rosmarinic acid content, authors used methanol, ethanol, acetone and their water solutions (AKOWUAH et al., 2005; ALMELA et al., 2006; AL et al., 1994; ZELIĆ et al., 2005). The best of rosmarinic acid yields was reached with $50 \%(\mathrm{v} / \mathrm{v})$ water solution of methanol or ethanol. Yield of extracted compounds is dependent on their solubility in solvent, which dependents on polarity of solvent. For the evaluation of solvent polarity the dielectric constant is used. Dependence of rosmarnic acid yields on dielectric constant (Fig. 1) was developed on the base evaluation extraction yields using methanol, ethanol, propan-2-ol and their water solutions (33 and $66 \%$; v/v) as extraction solvents. Dielectric constants were calculated according to Equation 2:

$$
\varepsilon_{\text {watersolution }}=\varepsilon_{\text {water }} * v_{\text {water }}+\varepsilon_{\text {alcohol }} * v_{\text {alcohol }},
$$

where $\varepsilon$ is dielectric constant of extraction solvents and $\mathrm{v}$ is volume coefficient of resulting solution used as extraction solvent.

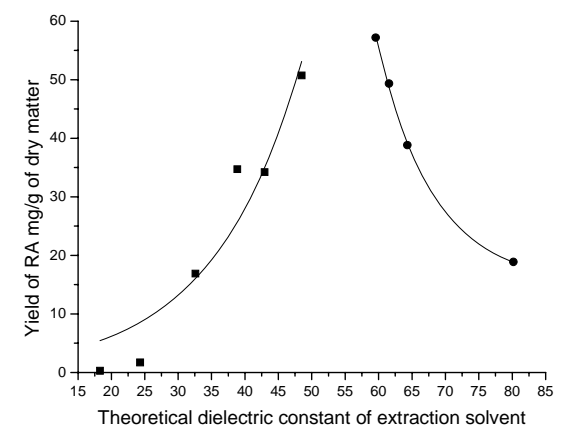

Fig. 1. Dependence of rosmarinic acid yield on theoretical dielectric constant of extraction solvent.

Results indicated that the biggest rosmarinic acid yields were obtained using solvent with dielectric constant in the range from 48 to 59 , which represented $33-47$ $\%$ water solution of propan-2-ol. Therefore, one of optimized parameter was concentration of propan-2-ol in water solution used as extraction solvent. Dependence 
of isolated compound yields on theoretical dielectric constant of extraction solvent is well-know from literature. Similar course of this dependence was observed at various natural compounds such as antibiotics (BORA and DUTTA, 2000) or pigments from paprika (KISS et al., 2000).

The impact of the solid-to-liquid ratio on the extraction of rosmarinic acid from M. officinalis was conducted with four ratios (1:10, 1:20, 1:30 and 1:40; w/v) during 1 hour at $80{ }^{\circ} \mathrm{C}$ with $33 \%(\mathrm{v} / \mathrm{v})$ water solution of propan-2-ol as extraction solvent. The results of the one-way analysis of variance showed that there was a significant difference among the ratios studied. There was no statistically significant difference between the ratios 1:30 and 1:40 (w/v). The solid-liquid ratio optimal for rosmarinic acid extraction is between the ratios 1:20 and 1:30 (w/v). This survey is consonant with literature (AKOWUAH et al., 2005; GEORGIEV et al., 2006; BASKAN et al., 2007).

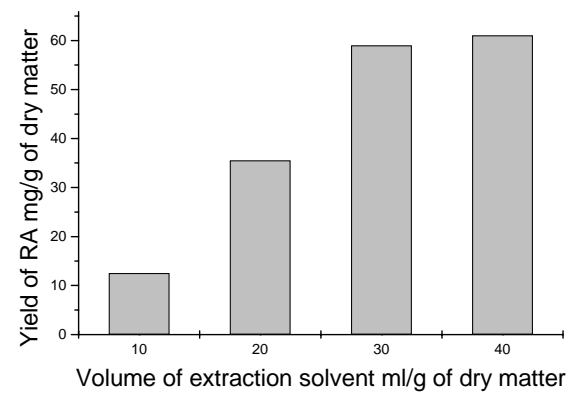

Fig. 2. Effect of the solid-liquid ratio on the extraction of rosmarinic acid from M. officinalis leaves over 1 hour with a $33 \%(\mathrm{v} / \mathrm{v})$ water solution of propan-2-ol at $80{ }^{\circ} \mathrm{C}$.

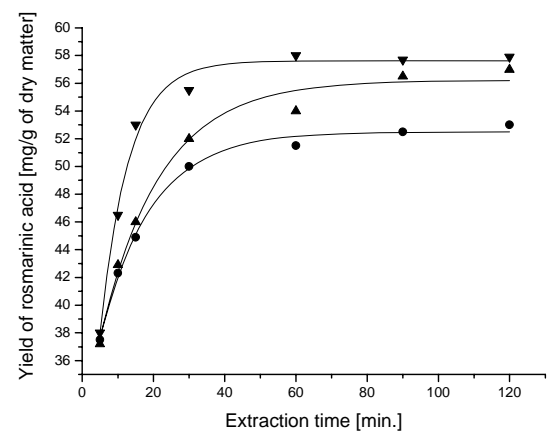

Fig. 3. Kinetics of rosmarinic acid extraction with a $33 \%(\mathrm{v} / \mathrm{v})$ water solution of propan-2-ol at various temperatures $\left(\bullet-40^{\circ} \mathrm{C} ; \boldsymbol{\Delta}-60^{\circ} \mathrm{C} ; \boldsymbol{\nabla}-80^{\circ} \mathrm{C}\right)$ by solid-liquid ratio 1:100.

From kinetics of rosmarinic acid extraction represented in Fig 3, it is evident, that maximum yield of rosmarinic acid was reached after $60 \mathrm{~min}$ of extraction for the three temperatures studied. The best bits were achieved using the exponential model, for the three temperatures and the range of time used, as expressed by the coefficients of determination $\left(\mathrm{R}^{2}\right)$ (Tab. 1). 
Table 1. Exponential models for the kinetic of rosmarinic acid extraction from $M$. officinalis leaves.

\begin{tabular}{ccccc}
\hline \multirow{2}{*}{ Temperature $\left({ }^{\circ} \mathrm{C}\right)$} & \multicolumn{4}{c}{$\mathrm{y}=\mathrm{a}+\mathrm{b}^{*} \exp (-\mathrm{x} / \mathrm{c})$} \\
\cline { 2 - 5 } & $\mathrm{a}$ & $\mathrm{b}$ & $\mathrm{c}$ & $\mathrm{R}^{2}$ \\
\hline 40 & $53.82 \pm 0.37$ & $-34.78 \pm 3.23$ & $16.76 \pm 1.67$ & 0.9752 \\
60 & $57.34 \pm 0.59$ & $-25.75 \pm 1.47$ & $18.95 \pm 2.46$ & 0.9788 \\
80 & $58.93 \pm 0.54$ & $-34.03 \pm 1.06$ & $9.22 \pm 1.15$ & 0.9556 \\
\hline
\end{tabular}

\subsection{Optimization of extraction by RSM}

The rosmarinic acid extraction from $M$. officinalis was optimized through the RSM approach. A fixed extraction time (1 hour) and a fixed particle size $(<0.5 \mathrm{~mm})$ were chosen. Results of rosmarinic acid yields for all runs are reported in Table 2.

Multiple linear regressions using the second-order polynomial model (Eq. 1) were performed in the results of Table 2 . The response variability was explained by the model, the coefficient of multiple determination $\left(\mathrm{R}^{2}\right)$ was 0.9253 .

\subsubsection{Analyses of the regression coefficients and the response surface}

The regression coefficients of the model for rosmarinic acid yield obtained by the multiple linear regression are reported in Table 3. Variables in their coded form (Table 2) permitted a direct interpretability of effects (linear, quadratic and interaction) of independent variables, and the surface plot (Fig. 4) facilitated the visualisation of the statistically significant factors (denoted by the superscript letters on the regression coefficients of Table 3 ) derived from the statistical analysis.

Table 2. Experimental results for the response variable (rosmarinic acid yield) and independent variables $\left(\mathrm{X}_{1}, \mathrm{X}_{2}\right.$ and $\left.\mathrm{X}_{3}\right)$ in original and coded form.

\begin{tabular}{ccccc}
\hline \multirow{2}{*}{$\begin{array}{c}\text { Standard } \\
\text { order }\end{array}$} & \begin{tabular}{c} 
Factor 1 $\left(\mathrm{X}_{1}\right)$ \\
\cline { 2 - 5 }
\end{tabular} & Factor 2 $\left(\mathrm{X}_{2}\right)$ & Factor 3 $\left(\mathrm{X}_{3}\right)$ & Factor Y \\
\hline 1 & $0.035(-1)$ & $20(-1)$ & $32(-1)$ & RA yield mg/g DM \\
2 & $0.035(-1)$ & $20(-1)$ & $68(1)$ & 38.71 \\
3 & $0.083(1)$ & $20(-1)$ & $32(-1)$ & 62.54 \\
4 & $0.083(1)$ & $20(-1)$ & $68(1)$ & 36.65 \\
5 & $0.035(-1)$ & $76(1)$ & $32(-1)$ & 33.52 \\
6 & $0.035(-1)$ & $76(1)$ & $68(1)$ & 21.04 \\
7 & $0.083(1)$ & $76(1)$ & $32(-1)$ & 55.98 \\
8 & $0.083(1)$ & $76(1)$ & $68(1)$ & 17.88 \\
9 & $0.059(0)$ & $48(0)$ & $20(-1.68)$ & 30.59 \\
10 & $0.059(0)$ & $48(0)$ & $80(1.68)$ & 21.68 \\
11 & $0.019(-1.68)$ & $48(0)$ & $50(0)$ & 55.79 \\
12 & $0.099(1.68)$ & $48(0)$ & $50(0)$ & 62.62 \\
13 & $0.059(0)$ & $1(-1.68)$ & $50(0)$ & 17.37 \\
14 & $0.059(0)$ & $95(1.68)$ & $50(0)$ & 53.73 \\
15 & $0.059(0)$ & $48(0)$ & $50(0)$ & 0.5 \\
16 & $0.059(0)$ & $48(0)$ & $50(0)$ & 62.62 \\
17 & $0.059(0)$ & $48(0)$ & $50(0)$ & 63.5 \\
& & & & 65.34 \\
\hline
\end{tabular}


Table 3. Regression coefficients of second-order model for dependent variable - rosmarinic acid yield.

\begin{tabular}{ccc}
\hline & Model parameters & RA yield \\
\hline Intercept & & -89.391 \\
\hline \multirow{2}{*}{ Linear } & Temperature & $\mathbf{3 . 5 2 4 8 9}$ \\
& Solid-liquid ratio & $\mathbf{1 8 3 7 . 3 4}$ \\
& Propan-2-ol & $\mathbf{0 . 7 8 0 9 7}$ \\
\hline \multirow{2}{*}{ Quadratic } & Temperature x temperature & $\mathbf{- 0 . 0 2 4 9 3}$ \\
& Solid-liquid ratio x solid-liquid ratio & $\mathbf{- 1 3 2 4 5 . 3}$ \\
& Propan-2-ol x propan-2-ol & $\mathbf{- 0 . 0 1 5 5 9}$ \\
\hline \multirow{2}{*}{ Interaction } & Temperature x solid-liquid ratio & -14.2332 \\
& Temperature x propan-2-ol & 0.00668 \\
& Solid-liquid ratio x propan-2-ol & 0.47061 \\
\hline
\end{tabular}

Regression coefficients with a statistically significant at $\mathrm{p}<0.05$ are printed in bold.

As indicated by the $\mathrm{p}$ value, regarding the propan-2-ol proportion $\left(\mathrm{X}_{2}\right)$, negative linear and quadratic effects were verified to be statically significant for rosmarinic acid yield. This result indicated that rosmarinic acid yield increases with decreasing of propan-2-ol proportion but quadratic effect of this variable parameter suggested forming of specific area whit maximal yield of rosmarinic acid. These results supported by results in first part of this study (an appropriate extraction solvent with dielectric constant between 48 and 55) and results of another study (DURLING et al., 2007). Negative linear and quadratic effects of solid-liquid ratio $\left(X_{1}\right)$ suggested that the increase of extraction solvent volume to extraction material mass improves the rosmarinic acid yield. Positive effect of temperature $\left(\mathrm{X}_{3}\right)$ was detected, which confirms that the increase in temperature improves the rosmarinic acid yield. Indeed, a higher temperature increases the solubility and diffusion coefficient of rosmarinic acid, allowing higher extraction rate.

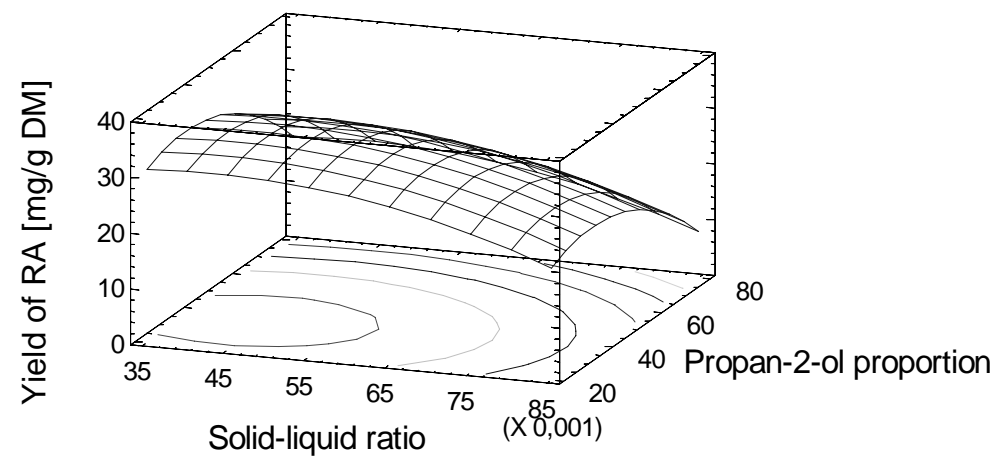

Fig. 4. Response surface plot for yield of rosmarinic acid, in function solid-to-liquid ratio and proportion of propan-2-ol in extraction solvent at $50{ }^{\circ} \mathrm{C}$.

\subsection{Determination and experimental validation of the optimal conditions}

In order to verify the predictive capacity of the model, an optimum condition was determined using the simplex method and the maximum desirability for the rosmarinic 
acid yield, and it was used for an extraction test (Table 4). The measured values lay within a $95 \%$ mean confidence interval of the predicted value for rosmarinic acid yields. These results confirm the predictability of the model for the extraction of rosmarinic acid from $M$. officinalis leaves in the experimental condition used.

Table 4. Comparison of predicted and experimental values at optimal conditions of rosmarinic acid extraction.

\begin{tabular}{cc}
\hline Optimized conditions & \\
\hline Propan-2-ol & 39 \\
Temperature $\left[{ }^{\circ} \mathrm{C}\right]$ & 66 \\
Solid-liquid ratio & 0.035 \\
Predicted value of rosmarinic acid yield $[\mathrm{mg} / \mathrm{g}]$ & $74.4 \pm 2.59$ \\
Experimental value of rosmarinic acid yield $[\mathrm{mg} / \mathrm{g}]$ & $72.6 \pm 3.12$ \\
\hline
\end{tabular}

\section{Conclusions}

The response surface methodology was successfully employed to optimize the rosmarinic acid extraction from $M$. officinalis leaves. The second-order polynomial model gave a satisfactory description of the experimental data. An optimized condition for maximum extraction of rosmarinic acid was determined. The optimal conditions were - propan-2-ol proportion $39 \%$, extraction temperature $66{ }^{\circ} \mathrm{C}$ and solid-liquid ratio $1: 29(\mathrm{w} / \mathrm{v})$. This study can by useful for the development of industrial extraction processes, including further studies concerning the optimal number of sequential steps to enhance the efficiency of a large-scale extraction system.

\section{References}

AKOWUAH, G. A., ISMAIL, Z., NORHAYATI, I., SADIKUN, A.: The effects of different extraction solvents of varying polarities on polyphenols of Orthosiphon stamineus and evaluation of the free radical-scavenging activity. Food Chem., 93, 2005, 311-313.

AL, CH. B., DENG, Q. H., SONG, W. Z., LI, L. N.: Salvianolic acid J, a depside from Salvia flava. Phytochemistry, 37, 1994, 907-908.

ALMELA, L., SANCHEZ-MUNOZ, B., FERNANDEZ-LOPEZ, J., ROCA, M. J., RABE, V.: Liquid chromatograpic-mass spectrometric analysis of phenolics and free radical scavenging activity of rosemary extract from different raw material. J. Chromatogr. A, 1120, 2006, 221-223

BASKAN, S., OZTEKIN, N., ERIM, F. B.: Determination of carnosic acid and rosmarinic acid in sage by capillary electrophoresis. Food Chem., 101, 2007, 17481751

BORA, M. M., DUTTA, N. N.: Extraction equilibria of cephalosporin antibiotics with aliquat-33. J. Chem. Eng. Data, 45, 2000, 399- 403

DURLING, N. E., CATCHPOLE, O. J., GREY, J. B., WEBBY, R. F., MITCHELL, K. A., FOO, L. Y., PERRY, N. B.: Extraction of phenolics and essential oil from 
dried sage (Salvia officinalis) using ethanol-water mixtures. Food Chem., 101, 2007, 1417-1424

GEORGIEV, M., KOVATCHEVA, E., MARCHEVA, N., ILIEVA, M.: purification rosmarinic acid extracts from Lavandula vera MM cell biomass. Food Chem., 94, 2006, 111-114

KISS, G. A. C., FORGÁCS, E., CSERHÁTI, T., MOTA, T., MORAIS, H., RAMOS, A.: Optimisation of the microwave-assisted extraction of pigments from paprika (Capsicum annuum L.) powders. J. Chromatogr. A, 889, 2000, 41-49.

SILVA, E. M., ROGEZ, H., LARONDELLE, Y.: Optimization of extraction of phenolics from Inga edulis leaves using response surface methodology. Separ. Purif. Technol., 55, 2007, 381-387

ZELIĆ, B., HADOLIN, M., BAUMAN, D., VASIĆ-RAČKI, D.: Recovery and purification of rosmarinic acid from rosemary using electrodialysis. Acta Chim. Slov., 52, 2005, 126-130 